\title{
Secondary tension pneumothorax in a COVID-19 pneumonia patient: a case report
}

\author{
Judith E. Spiro ${ }^{1} \cdot$ Snezana Sisovic ${ }^{2} \cdot$ Ben Ockert $^{3} \cdot$ Wolfgang Böcker $^{3} \cdot$ Georg Siebenbürger $^{3}$ (i)
}

Received: 20 April 2020 / Accepted: 27 May 2020 / Published online: 18 June 2020

(c) The Author(s) 2020

\begin{abstract}
Purpose Especially in elderly and multimorbid patients, Coronavirus Disease 2019 (COVID-19) may result in severe pneumonia and secondary complications. Recent studies showed pneumothorax in rare cases, but tension pneumothorax has only been reported once.

Case presentation A 47-year-old male was admitted to the emergency department with fever, dry cough and sore throat for the last 14 days as well as acute stenocardia and shortage of breath. Sputum testing (polymerase chain reaction, PCR) confirmed SARS-CoV-2 infection. Initial computed tomography (CT) showed bipulmonary groundglass opacities and consolidations with peripheral distribution. Hospitalization with supportive therapy (azithromycin) as well as non-invasive oxygenation led to a stabilization of the patient. After 5 days, sputum testing was negative and IgA/IgG antibody titres were positive for SARS-CoV-2. The patient was discharged after 7 days.

On the 11th day, the patient realized pronounced dyspnoea after coughing and presented to the emergency department again. CT showed a right-sided tension pneumothorax, which was relieved by a chest drain (Buelau) via mini open thoracotomy. Negative pressure therapy resulted in regression of the pneumothorax and the patient was discharged after 9 days of treatment. Conclusion Treating physicians should be aware that COVID-19 patients might develop severe secondary pulmonary complications such as acute tension pneumothorax.
\end{abstract}

Level of evidence $\mathrm{V}$

Keywords COVID-19 $\cdot$ Pneumothorax $\cdot$ Pneumonia $\cdot$ Multidetector computed tomography $\cdot$ Viral infections

\section{Background}

Since its first description in Wuhan, Hubei Province, China, in December 2019, severe acute respiratory syndrome coronavirus 2 (SARS-CoV-2) has led to a pandemic, which was

Electronic supplementary material The online version of this article (https://doi.org/10.1007/s15010-020-01457-w) contains supplementary material, which is available to authorized users.

Georg Siebenbürger

georg.siebenbuerger@med.uni-muenchen.de

1 Department of Radiology, University Hospital, LMU Munich, Munich, Germany

2 Department of Internal Medicine IV-Endocrinology, Munich University Hospitals, Ludwig-Maximilians-University, Munich, Germany

3 Department of General, Trauma and Reconstructive Surgery, Munich University Hospitals, Ludwig-Maximilians-Universi ty, Nussbaumstr. 20, 80336 Munich, Germany officially declared a global health emergency by the world health organization (WHO) on January 30, 2020 [1, 2]. Coronavirus disease 2019 (COVID-19) may lead to severe viral pneumonia. Characteristic computed tomography (CT) findings in affected patients include bilateral, multilobar groundglass opacities (GGO) and consolidations with peripheral and posterior distribution [3-6]. Aside from common symptoms like dry cough, fever, myalgia and/or fatigue, severe secondary complications are described in recently published studies: acute respiratory distress syndrome (ARDS), acute kidney or cardiac injury, secondary infection and liver dysfunction [7]. Reports of pneumothorax as a complication of COVID-19 are rare, and therefore, we describe a case of secondary tension pneumothorax. 


\section{Case report}

A 47-year-old male was admitted to our emergency department with dry cough, shortness of breath and stenocardia. Body temperature on initial admission was $37.9{ }^{\circ} \mathrm{C}$. Due to a traumatic motorcycle accident, the patient had undergone splenectomy years ago. Because of human immunodeficiency virus (HIV) infection, the patient was under treatment with Dovato ${ }^{\circledR} 50 / 300 \mathrm{mg}\left(\mathrm{GSK}^{\circledR}\right.$, Dolutegravir/ Lamivudine). Nadir CD4 count was 573 cells/ $\mu \mathrm{L}$ (23\% of lymphocytes) and lowest CD4/CD8 ratio 0.472 days after hospitalization compared to 1210 cells ( $29 \%$ of lymphocytes) and a CD4/CD8 ratio of 0.74 at time of admission. One month before, at a regular check-up, CD 4 count was 1408 cells/ $\mu \mathrm{L}$ (35\% of lymphocytes) and CD4/CD8 ratio 0.9 . The patient had no previously known pulmonary or thoracic diseases and no history of smoking. There was no recent history of travel to a designated COVID-19 risk area, but contact to an infected individual in the patients' social environment. Symptoms including dry cough, fever, shortness of breath and stenocardia had lasted for 14 days before primary admission.

Blood gas analysis (arterial) at admission showed a $\mathrm{pH}$ of $7.49, \mathrm{PCO}_{2}$ of $32.6 \mathrm{mmHg}, \mathrm{PO}_{2}$ of $110 \mathrm{mmHg}$, and $\mathrm{SaO}_{2}$ at $98.9 \%$ with $5 \mathrm{~L} / \mathrm{min}$ oxygen applied by nasal cannula, which was hence reduced to $3 \mathrm{~L} / \mathrm{min}$ oxygen, resulting in a peripheral $\mathrm{O}_{2}$ saturation of $95 \%$.

Polymerase chain reaction (PCR) tests of nasal and pharyngeal swabs and sputum were positive for SARSCoV-2-RNA N-gene 1, but negative for RSV, Influenza$A$ and Influenza-B. HIV-1-RNA testing (PCR) showed a level of $<40$ copies/mL.
Blood samples showed increased levels of CRP (10.2 mg/d), lactate dehydrogenase (LDH) (406 U/L), leucocytes $(12.4 \mathrm{G} / \mathrm{L})$, D-dimers $(1.7 \mu \mathrm{g} / \mathrm{mL})$, and interleukine-6 (122 pg/mL). Procalcitonin (PCT) levels were $\leq 0.1 \mathrm{ng} / \mathrm{mL}$. Neutrophil count was reduced to $35.0 \%$ and lymphocyte count was normal (46\%).

The electrocardiogram was normal. Troponin $\mathrm{T}(\mathrm{hs})$ was negative $(\leq 0.013)$.

CT scan at admission showed bipulmonary GGO and consolidations with a multilobar, peripheral and dorsal distribution. Pulmonary embolism, suspected due to elevated levels of D-dimers, was ruled out. Detailed information about the radiological appearance and follow-up of the patient can be found in the supplement.

Because of progressive coughing and shortness of breath, the patient received $3 \mathrm{mg}$ of morphine and was admitted to the intermediate care ward. Further therapy consisted of azithromycin to prevent secondary bacterial superinfection. Antibody titres (Anti-SARS-CoV-2-IgG and Anti-SARSCoV-2-IgA) were positive and SARS-CoV-2-RNA N-gene 1 (PCR) was negative 5 days after primary admission. The patient was discharged with lowering CRP levels as well as normalized leucocytes and interleukine-6 levels after 7 days.

Four days later, 11 days after primary admission, the patient admitted again to the emergency department with pronounced dyspnoea after coughing.

Blood gas analysis (arterial) showed a $\mathrm{pH}$ of 7.47, $\mathrm{PCO}_{2}$ of $33 \mathrm{mmHg}, \mathrm{PO}_{2}$ of $64 \mathrm{mmHg}$, and $\mathrm{SaO}_{2}$ of $94 \%$ with $3 \mathrm{~L} /$ min oxygen applied by nasal cannula. Clinical elevation showed a reduced right sided breathing sound. The electrocardiogram showed tachycardia (103 bpm).

Thoracic CT revealed a right-sided tension pneumothorax (Fig. 1a). To relieve the tension pneumothorax, a small caliber chest tube (20 Charrière $=$ French, Buelau $)$ was

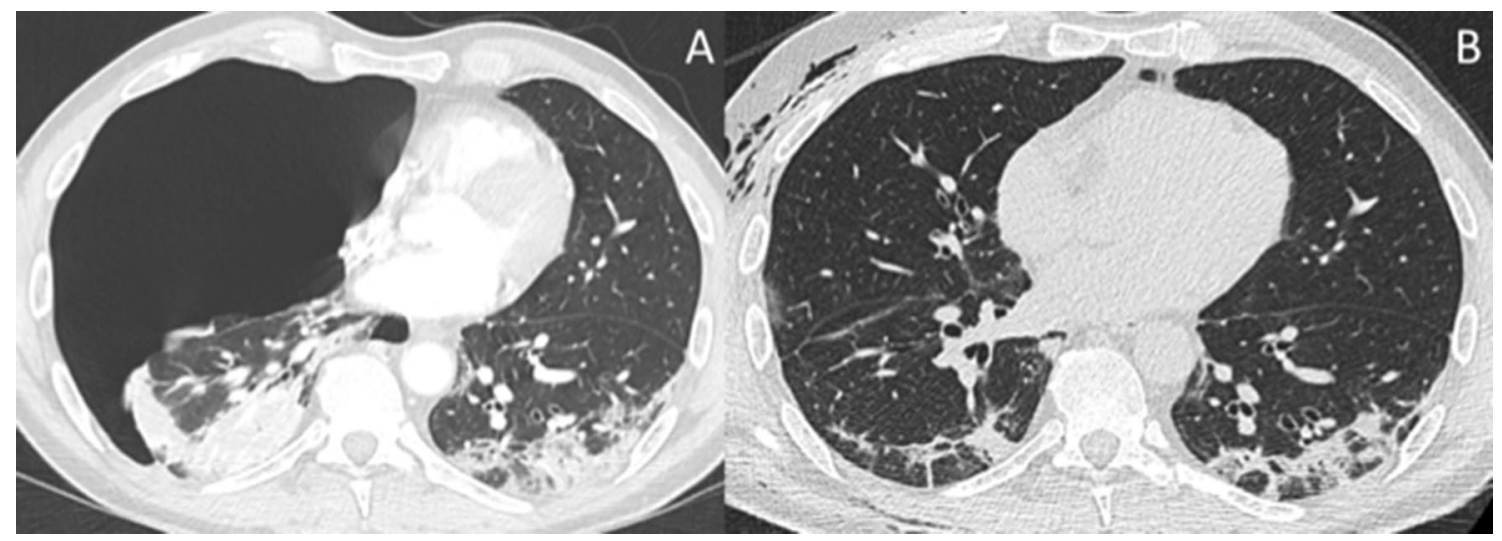

Fig. 1 Axial CT images obtained with intravenous contrast at second admission show a right-sided tension pneumothorax with mediastinal shift to the left and right heart compression (a). Unenhanced axial CT images obtained 8 days after second admission show remission of tension pneumothorax, new soft tissue emphysema of the right chest wall and mild pneumomediastinum (b). Bilateral GGO and consolidations with peripheral distribution on both images are signs of COVID-19 pneumonia. CT, computed tomography; GGO, ground glass opacities 


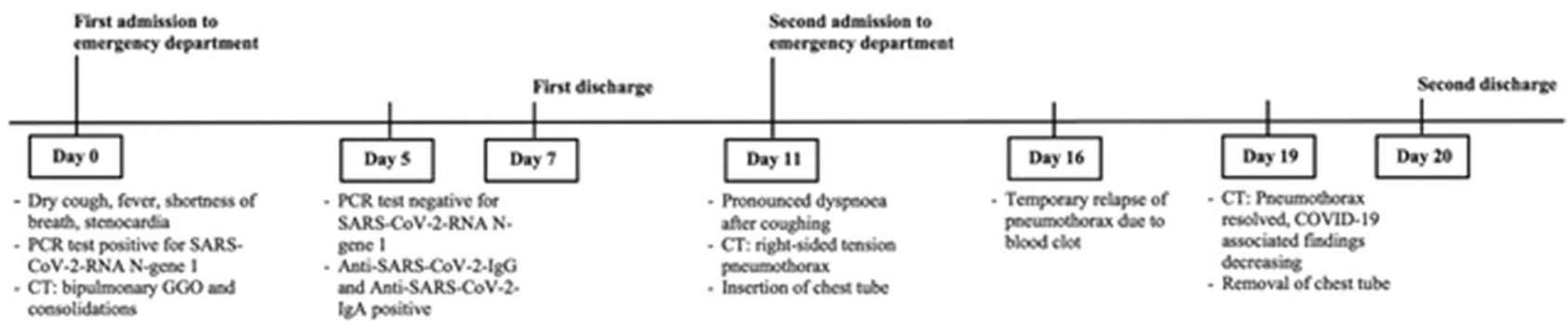

Fig. 2 Timeline of the patient history from first admission to second discharge. COVID-19, Coronavirus Disease 2019. CT, computed tomography. GGO, ground glass opacities. PCR, polymerase chain

inserted through a mini open thoracotomy in the 5th right intercostal space. Due to secondary displacement, the drain had to be repositioned $4 \mathrm{~h}$ later. Continuous negative pressure $\left(-20 \mathrm{~cm} / \mathrm{H}_{2} \mathrm{O}\right)$ led to almost complete regression of the pneumothorax. Five days later, clogging of the chest drain by a blood clot caused brief worsening of the patient's status with relapse of the pneumothorax and increasing soft tissue emphysema. When the clot was removed, the pneumothorax resolved again. Follow-up CT 8 days after second admission confirmed good re-expansion of the right lung, residual soft tissue emphysema of the right chest wall and mild pneumomediastinum (Fig. 1b).

The chest tube was removed after 8 days and the patient was discharged after 9 days ( 20 days after primary admission) in stable condition.

A timeline of the events is presented in Fig. 2.

\section{Discussion}

Its relatively high sensitivity and availability have made CT of the chest an important screening tool for COVID-19, especially when PCR testing capacities are limited. Characteristic CT findings include pulmonary GGO and consolidations, often with a bilateral, dorsal and subpleural distribution. Additionally, thoracic CT plays an important role in the follow-up of COVID-19 patients, because it allows evaluation of the course of disease as well as detection of acute complications, such as pulmonary embolism and pneumothorax [8-10].

To date, spontaneous pneumothorax has been seldom reported in patients with COVID-19. In one case from Wuhan, formation of subpleural bullae was observed on chest $\mathrm{CT}$ as a possible cause for development of mediastinal emphysema and pneumothorax [9]. Our patient, however, did not show pulmonary cysts or bullae on CT scans, neither before onset, nor after treatment of tension pneumothorax. Tension pneumothorax after infection with SARS-CoV-2 has been described only once before in a recently published case report by Flower et al. [11] Larger studies showed a reaction. RNA, ribonucleic acid. SARS-CoV-2, severe acute respiratory syndrome coronavirus 2

pneumothorax prevalence of $1-2 \%$ in adults with COVID$19[4,7,12,13]$.

Spontaneous pneumothorax is a commonly known complication in patients with ARDS, where the most frequent causes are pressure and volume-related alveolar rupture [14]. Histological examination of lung biopsy samples in a patient who died from COVID-19 pneumonia showed desquamation of pneumocytes and hyaline membrane formation, indicating ARDS [7]. Before onset of severe dyspnea, our patient suffered from coughing, which increases alveolar pressure. Considering the absence of pre-existing pulmonary conditions as well as a negative smoking history, in this case we suspect the pneumothorax to be caused by the structural lung injury following a COVID-19 pneumonia.

\section{Conclusion}

We present a rare but severe complication of infection with SARS-CoV-2. The case of secondary tension pneumothorax underlines the importance of prompt and thorough clinical evaluation of COVID-19 patients with worsening respiratory status.

Acknowledgements Open Access funding provided by Projekt DEAL. We thank the patient for granting us permission to publish this information.

Author contributions All authors contributed to the study conception and design. JES, SS and GS performed material preparation, data collection and analysis. GS wrote the first draft of the manuscript and all authors commented on previous versions of the manuscript. All authors read and approved the final manuscript.

Funding This manuscript was not funded.

Data availability All available information is contained within the manuscript. 


\section{Compliance with ethical standards}

Conflict of interest On behalf of all authors, the corresponding author states that there are no conflicts of interest.

Ethical approval Ethics approval was not obtained due to clinical standard treatment.

Informed consent Written informed consent was obtained from the patient.

Consent for publication Written informed consent was obtained from the patient for publication of this case and any accompanying images. A copy of the written consent is available for review by the Editor of this journal.

Open Access This article is licensed under a Creative Commons Attribution 4.0 International License, which permits use, sharing, adaptation, distribution and reproduction in any medium or format, as long as you give appropriate credit to the original author(s) and the source, provide a link to the Creative Commons licence, and indicate if changes were made. The images or other third party material in this article are included in the article's Creative Commons licence, unless indicated otherwise in a credit line to the material. If material is not included in the article's Creative Commons licence and your intended use is not permitted by statutory regulation or exceeds the permitted use, you will need to obtain permission directly from the copyright holder. To view a copy of this licence, visit http://creativecommons.org/licenses/by/4.0/.

\section{References}

1. Zhu N, Zhang D, Wang W, Li X, Yang B, Song J, et al. A novel coronavirus from patients with pneumonia in China, 2019. N Engl J Med. 2020;382:727-33. https://doi.org/10.1056/NEJMoa2001 017.

2. Salzberger B, Gluck T, Ehrenstein B. Successful containment of COVID-19: the WHO-Report on the COVID-19 outbreak in China. Infection. 2020;48:151-3. https://doi.org/10.1007/s1501 0-020-01409-4.

3. Wu J, Wu X, Zeng W, Guo D, Fang Z, Chen L, et al. Chest CT findings in patients with coronavirus disease 2019 and its relationship with clinical features. Invest Radiol. 2020;55:257-61. https ://doi.org/10.1097/RLI.0000000000000670.
4. Salehi S, Abedi A, Balakrishnan S, Gholamrezanezhad A. Coronavirus Disease 2019 (COVID-19): a systematic review of imaging findings in 919 patients. AJR Am J Roentgenol. 2020. https://doi. org/10.2214/AJR.20.23034.

5. Ye G, Pan Z, Pan Y, Deng Q, Chen L, Li J, et al. Clinical characteristics of severe acute respiratory syndrome coronavirus 2 reactivation. J Infect. 2020. https://doi.org/10.1016/j.jinf.2020.03.001.

6. Cheng ZJ, Shan J. 2019 Novel coronavirus: where we are and what we know. Infection. 2020;48:155-63. https://doi.org/10.1007/ s15010-020-01401-y.

7. Yang X, Yu Y, Xu J, Shu H, Xia J, Liu H, et al. Clinical course and outcomes of critically ill patients with SARS-CoV-2 pneumonia in Wuhan, China: a single-centered, retrospective, observational study. Lancet Respir Med. 2020. https://doi.org/10.1016/S2213 -2600(20)30079-5.

8. Pan Y, Guan H, Zhou S, Wang Y, Li Q, Zhu T, et al. Initial CT findings and temporal changes in patients with the novel coronavirus pneumonia (2019-nCoV): a study of 63 patients in Wuhan. China Eur Radiol. 2020. https://doi.org/10.1007/s00330-02006731-x.

9. Rubin GD, Ryerson CJ, Haramati LB, Sverzellati N, Kanne JP, Raoof S, et al. The Role of chest imaging in patient management during the COVID-19 pandemic: a multinational consensus statement from the fleischner society. Radiology. 2020. https://doi. org/10.1148/radiol.2020201365.

10. Bernheim A, Mei X, Huang M, Yang Y, Fayad ZA, Zhang N, et al. Chest CT findings in coronavirus disease-19 (COVID-19): relationship to duration of infection. Radiology. 2020. https://doi. org/10.1148/radiol.2020200463.

11. Flower L, Carter JL, Rosales Lopez J, Henry AM. Tension pneumothorax in a patient with COVID-19. BMJ Case Rep. 2020. https ://doi.org/10.1136/bcr-2020-235861.

12. Sun R, Liu H, Wang X. Mediastinal emphysema, giant bulla, and pneumothorax developed during the course of COVID-19 pneumonia. Korean J Radiol. 2020. https://doi.org/10.3348/ kjr.2020.0180.

13. Chen N, Zhou M, Dong X, Qu J, Gong F, Han Y, et al. Epidemiological and clinical characteristics of 99 cases of 2019 novel coronavirus pneumonia in Wuhan, China: a descriptive study. Lancet. 2020;395:507-13. https://doi.org/10.1016/S0140-6736(20)30211 $-7$.

14. Woodside KJ, vanSonnenberg E, Chon KS, Loran DB, Tocino IM, Zwischenberger JB. Pneumothorax in patients with acute respiratory distress syndrome: pathophysiology, detection, and treatment. J Intensive Care Med. 2003;18:9-20. https://doi. org/10.1177/0885066602239120. 